\title{
EL MODELO CONSOCIONAL \\ EN LA POLÍTICA DEL FUTURO
}

Alberto Arce E.*

En una primera aproximación al tema, haremos una breve descripción de lo que se denomina: modelo "consocional" y sus efectos en el concepto y práctica del negocio político. Si bien es cierto el modelo "consocional" aparece en su origen como una proposición para la participación de todos los grupos coexistentes en una sociedad plural dividida, los efectos y modalidades de la negociación política podrían ser de una aplicación general.

En el seno de toda sociedad política existen divisiones, pero éstas siempre pueden ser separadas si existe una conciencia real y definidá del interés nacional; esta conciencia única es difícil de desarrollar en las sociedades conformadas por distintas nacionalidades o grupos culturales.

Las medidas aplicadas por las sociedades plurales a fin de lograr una participación equitativa de los segmentos que las componen, ofrecen una serie de novedades que resulta interesante observar para un uso más generalizado.

Pocos países del mundo cuentan con una homogeneidad racial, cultural e histórica que permiten que la idea de "una nación un estado" pueda hacerse factible con relativamente pocos problemas, comparado con las sociedades plurales.

II

Al tratar el tema de la crisis del Estado, Freund cuestiona la legitimidad del poder,

* El autor, abogado y politólogo, actualmente pertenece al Servicio de Relaciones Exteriores. 
estableciendo que éste es legítimo "cuando dispone de un amplio consenso en la población, la cual adhiere a los principios del ejercicio de la libertad política definidos en la Constitución" ". Agrega que el ciudadano ve la condición de legitimidad en la medida que se respetan sus derechos y libertades. La pérdida del consenso significa el gradual ascenso de la pérdida de la legitimidad, asumiendo el poder político carácter de tiránico. El conflicto social nace al producirse la relación antagónica entre las aspiraciones políticas del individuo y los objetivos de quienes manejan el poder político que confiere el aparato estatal.

La crisis de la legitimidad del poder político pareciera ser más evidente hoy en dia en las democracias liberales, a raíz de la popularidad creciente del principio del gobierno de las mayorías, sobre las minorías. Las democracias occidentales que operan por la voluntad de las mayorías son necesariamente inestables y vulnerables, desde el momento en que las minorías quedan excluidas de toda participación.

Los fundamentos para sustentar la democracia desde la fuerza superior de las mayorías son: teorías del derecho natural, la teoría del contrato social, ficciones legales o funciones pragmáticas; finalmente, suele argumentarse que la única alternativa sería el gobierno de las minorías y ello resulta no tener ninguna justificación teórica o pragmática toda vez que repugna al concepto general de las libertades democráticas.

Las teorías constitucionalistas pretenden fijar el fiel de la balanza estableciendo limitaciones y controles al ejercicio abusivo del poder y proteger de alguna manera el derecho de las minorías. Pero la práctica ha demostrado sólo un éxito relativo frente al abuso del poder y ninguna solución al problema de la participación de los excluidos.

"El ganador se lleva todo" ha sido el resultado tradicional, quedando el perdedor sólo en la posibilidad de centrar su actividad política en una oposición tendiente a hacer fracasar al adversario y así volcar la voluntad ciudadana a su favor, constituyéndose en una mayoría opositora; la legitimidad del poder es cuestionada y la sociedad entra en una crisis de la cual sólo se podría salir en la siguiente elección.

Si los problemas de legitimidad se presentan con gobiernos por simple mayoría, la crisis de legitimidad es tanto mayor en gobiernos de un tercio, como fue el caso del período 70-73. El gobierno de Allende careció de legitimidad desde el primer día y el poder político le fue atribuido simplemente por una ficción legal de representatividad parlamentaria. (La ficción de que la mayoría parlamentaria reflejaba la voluntad ciudadana en virtud de mandatos que en su esencia ya habían variado).

La experiencia chilena de gobiernos democráticos y liberales de mayorías ha

1 Freund, Julien: "Estudios sobre el Estado" U. de Chile, Stgo. 
demostrado que a la larga se logra dividir la sociedad política en términos irreconciliables. Si a ello se agrega la coexistencia de ideologías totalmente contrapuestas, más se acentúa la segmentación política.

Sin entrar a un análisis detallado de las diversas acepciones del concepto de pluralismo (ideológico, coexistencia de grupos intermedios o de grupos culturales, étnicos y hasta nacionalidades distintas) el imperio mayoritario en una sociedad de este tipo implica exclusión. Ello, como ya se ha señalado, significa a su vez pérdida de legitimidad por falta de un consenso general y por lo tanto inestabilidad de todo el sistema. Esta discusión ha sido reabierta por Lijphart ${ }^{2}$ con su proposición de "consotional democracy" o "konkordanz demokratie"; los pocos autores que han tratado el tema aún no se ponen de acuerdo si llamarlo en castellano: "democracia consocional", "democracia de consenso social", "democracia de concordancia", "democracia de consenso" o "democracia de participación"; aquí usaremos el término "democracia consocional".

El planteamiento de Lijphart se refiere a sociedades pluralistas altamente divididas por diferencias étnicas, culturales y antropológicas. Sin embargo, él mismo sugiere la aplicabilidad de algunos de sus elementos a otros tipos de sociedades divididas sin importar si los sistemas políticos son federados, unitarios, presidenciales o parlamentarios, etc. Lo importante es superar los vicios mayoritarios, la exclusión de segmentos sociales y otorgar una base más permanente a la legitimidad del poder político. La fórmula consocional, más que la proposición de una democracia de alternativa, formula una nueva participación política en la toma de decisiones.

En su investigación, Lijphart ha estudiado 22 sociedades en las cuales elementos consocionales han sido aplicados en la solución de problemas. En su lista figuran India, Bélgica, Alemania Occidental (con la "Gran Coalición" entre socialdemócratas y democratacristianos), Holanda (cuando enfrentó la invasión alemana), etc.

Al enumerar los elementos de la democracia "consocional" que limitan el sistema de mayorias, Lijphart señala ocho elementos observados:

1. Poder ejecutivo compartido (Gran Coalición).

2. Separación de poderes, formal e informal (dispersión de poder).

3. Equilibrio bicameral y representación de minorías.

4. Sistema multipartidario (eliminación de mayoría absoluta).

5. Sistema de partidos multidimensional (los partidos suelen ser integrados por miembros de diversas iglesias, patrones culturales, etc.).

6. Representación proporcional.

2 Lijphart, Arand: Democracias - Yale, N.Y., 1984. 
7. Federalismo territorial (delegación de poder), no territorial, descentralización.

8. Constitución escrita y veto de minoría (limitación de poder formal).

En su estudio comparativo Lijphart tomó como modelo de democracia de mayorías los sistemas "westminterianos" de Inglaterra y Nueva Zelandia y como sistemas "consocionales" Suiza y Bélgica.

No obstante esta descripción de ocho elementos, los autores que han tratado el tema suelen reducirlos a cuatro esenciales que son: "gran coalición", "veto mutuo", "proporcionalidad", "autonomía de los segmentos", los que analizamos a continuación.

III

El primer sentido de democracia según Sir Arthur Lewis ${ }^{3}$ es que "todos los que son afectados por una decisión deben tener la oportunidad de participar en la toma de decisión, ya sea directamente o representados". El segundo sentido es que "debe prevalecer la voluntad de la mayoria". Lewis agrega que ambos principios son incompatibles. Excluir a los grupos perdedores de la participación en la toma de decisiones viola claramente el primer sentido del término. Debemos notar que estamos comenzando a hablar de participación en la toma de decisiones y no sólo del proceso legislativo que, desde el punto de vista chileno, es el marco de referencia para el poder político.

Lo que las sociedades necesitan es un régimen democrático que enfatice el consenso en lugar de la oposición; que incluya en lugar de excluir.

El modelo de consenso señala esencialmente cuatro elementos restrictivos del imperio mayoritario excluyente.

\section{Gran Coalición}

La característica y el requisito más importante para la existencia de un sistema "consocional" es la Ilamada Gran Coalición, es un órgano en el cual los líderes de todos los grupos significativos de la sociedad se encuentran representados. Considerando la necesidad de consenso, es necesaria una estrecha cooperación entre los líderes de las distintas elites, sean éstas políticas, socioeconómicas, culturales o raciales, que realicen un considerable y pragmático esfuerzo para superar las divisiones a nivel masivo, para ello se requiere de una Gran Coalición, en la cual deben participar todos los grupos proporcionalmente con, a lo menos, un representante para el grupo más pequeño. El número de líderes de esta cúpula debe ser lo más reducido que la representatividad determine.

3

Premio Nobel de Economía. 
El ámbito de competencia de la Gran Coalición puede abarcar todos los asuntos o sólo algunos de interés nacional. En esta cúpula es donde comienza a desarrollarse un poder ejecutivo compartido.

El típico ejemplo de Gran Coalición que se cita es el de coalición de gabinete del sistema ejecutivo nacional suizo, que opera en el consejo federal. Este cuerpo consiste de siete miembros elegidos por los principales partidos políticos en proporción a su fuerza electoral y la presidencia es rotativa entre sus miembros cada año. Aun siendo la Gran Coalición el elemento central de la proposición consocional su eficacia va a depender de los demás elementos.

\section{Veto mutuo}

Si la Gran Coalición habilita a todos los grupos para participar en el proceso de toma de decisiones, la disponibilidad de un Veto Mutuo habilita a los grupos para influir en la toma de decisiones. El Veto Mutuo tiene un doble aspecto: por una parte obliga a la unanimidad o consenso en la decisión y por otra permite a la minoría proteger sus intereses esenciales frente a las mayorías. La posibilidad del ejercicio del veto obliga a las partes a agotar todas las posibilidades de negociación y compromiso.

Los aspectos bajo los cuales se puede analizar el veto y su reglamentación son numerosos; pueden referirse a materias generales o específicas, puede afectar solamente intereses vitales para los grupos y puede operar a niveles nacionales 0 sólo regionales; cualquiera que sea su ámbito de aplicación en esencia puede ser ejercido por todos los grupos en plano de reciprocidad. El abuso del veto puede fácilmente convertirse, para quien lo ejerza indiscriminadamente, en arma de doble filo. La posibilidad de su ejercicio pone a las partes en un plano de igualdad en la defensa de sus intereses, derrotando a la mayoría aplanadora. El peligro del veto es la posibilidad de ocasionar un inmovilismo político o mantención del statu quo; sin embargo, no debemos olvidar que la institucionalización del veto es materia de mecanismos de regulación que puedan hacer efectivo su ejercicio, su institucionalización puede hacerse como una práctica política o como una disposición constitucional. Los autores lo recomiendan para aquellas sociedades que no están habituadas al compromiso político y a la negociación con una base constitucional, como lo fue, en el período "consocional" de El Líbano, entre cristianos y musulmanes, en el poder legislativo.

\section{Proporcionalidad}

El principio de la Proporcionalidad ha sido considerado tradicionalmente en los sistemas electorales y a su incidencia consecuente en la representatividad de las diferentes tendencias políticas en los cuerpos legislativos. 
En el caso de la proposición "consocional" el principio de la Proporcionalidad tiene alcances mayores.

Las partes involucradas en el fenómeno político se sustentan en el principio de la Proporcionalidad, pero no sólo para los efectos de determinar sus representantes, sino además para establecer:

a) su participación en la toma de decisiones;

b) su influencia en la toma de decisiones;

c) su participación en la ejecución de las decisiones tomadas;

d) su participación en el ejercicio del poder político.

Los efectos de este concepto son múltiples; un grupo minoritario puede definir los recursos financieros necesarios para su segmento (sea éste cultural, racial, religioso, geográfico, etc.). Significa que no sólo el grupo que tiene mayoría participa de la administración pública, sino que también los demás grupos. De esta manera hasta el grupo más minoritario tiene derecho a nombramientos en la administración. Es un hecho real en la administración política que la existencia de cargos ejecutivos no son resultado de una elección popular. El principio de la Proporcionalidad, llevado al nivel de designaciones, contribuye a que los no ganadores participen del sistema y no se conviertan en erosionadores del mismo.

En el nivel de toma de decisiones, el principio de la Proporcionalidad debe ser considerado en relación al derecho a veto. En las democracias "consocionales" se han desarrollado diversas técnicas en la toma de decisiones para superar posibles impasses que se podrían producir. Una de las técnicas es la llamada de la "negociación en paquete" en que se acuerda simultáneamente respecto de un número amplio de medidas conexas que establecen compensaciones que impiden un perfil de ganadores o perdedores. Otra técnica suele ser la postergación de decisiones o el traslado a comisiones asesoras. Este último caso es el de la "Koalitionanschluss" austríaca.

Existen dos variaciones de la proporcionalidad: la llamada sobrerrepresentación calculada de las minorías y la paridad, es decir, que todos los grupos tengan la misma representación. Cualquiera de estos sistemas reduce la utilización del veto y su eventual abuso.

\section{Autonomia de los segmentos}

La Autonomía de los Segmentos, sean éstos geográficos, raciales, religiosos o de cualquier tipo, implica autonomía en el manejo de los asuntos propios, centrándose la decisión "consocional" en el nivel de las materias consideradas de interés nacional. Así, por ejemplo, en una sociedad dividida por razones raciales, cada grupo racial deberá poseer suficiente autonomía para resolver materias de su exclusiva atingencia de acuerdo a sus propios intereses culturales. Igual cosa si la 
segmentación es de carácter geográfico. De aquí que la fórmula "consocional" se pueda dar con mayor facilidad en sistemas políticos federados.

IV

Algunos cientistas políticos señalan las siguientes desventajas y defensas de la proposición "consocional":

1. El sistema entero descansa en una confianza excesiva en los líderes de las elites y la importancia otorgada a la cooperación, la negociación y el compromiso; si se encontrara ausente la vocación de servicio público, conducirían a corrupción y desarrollo de camarillas políticas con consecuencias desastrosas en la cúpula.

Los defensores de la proposición "consocional" señalan que en esta crítica se confunden la validez de un sistema abstracto con las cualidades o defectos morales de las personas. $Y$ como en todo sistema político, la única manera de evitar los vicios personales sería a través de controles y normas adecuadas que hagan efectiva la responsabilidad.

La crítica más seria es la posibilidad de negociación a puerta cerrada de un cartel elitesco, sin participación de los que se presume que están participando y sin acceso a la información. En un proceso de negociación, sin publicidad o difusión informativa, los líderes pueden ser considerados apóstatas de los mandatos segmentales si los mandantes no tienen conocimiento del proceso de negociación. Ergo, los problemas de no participación serían mayores que en las democracias basadas en mayorías excluyentes de minorías. Sin embargo, la negociación a puerta cerrada aparece para el sistema "consocional" como un elemento importante, ya que permite la despolitización de los temas y elimina la presión y el mal uso de los medios de comunicación y propaganda. Si la discusión fuera abierta los grupos débiles, sin control o acceso a los medios de comunicación, estarían en desventaja en la toma de decisiones (considerando a los medios como instrumento manipulativo de la opinión pública y no como elemento informativo de ella). Para los "consocionalistas" la discusión a puerta cerrada es de vital importancia para lograr la pureza de la decisión a la luz del interés general. No es así para los detractores del "consocionalismo" que ven con ello la eliminación de un poder contralor.

2. Una gran crítica a las desventajas que ocasiona el antimayoritarismo "consocional" es que produce un gobierno lento e inefectivo e incluso un inmovilismo total. La Gran Coalición y el principio del Veto pueden conducir a una situación de estancamiento total frustrando todo intento de reforma o modificación, lo que llevaría a una consolidación absoluta del statu quo y a la perpetuación de las actuales diferencias y explotaciones socioeconómicas de la sociedad de que se trate. 
Si consideramos que el cambio social es resultado de un proceso que, al no encontrar sus propios cauces de realización, produce una acumulación de presión social, el statu quo del "consocionalismo" llevaría en sí el germen del estallido revolucionario. Esta argumentación es a su vez rebatida señalando que las elites son pragmáticas por naturaleza y que la presión externa movería al consenso, evitando el estancamiento.

3. Un tercer grupo de críticas al "consocionalismo" dice relación con la segmentación o división de la sociedad en grupos. Un sistema político basado en la división de la sociedad en grupos, ya sean éstos raciales, culturales, religiosos, idiomáticos o ideológicos, lo único a que contribuye es a aumentar la división, destruyendo toda posibilidad de unidad; para estos criticos el "consocionalismo" es una enfermedad más del pragmatismo politico; es decir, institucionalizar las diferencias. Demás está decir que muchos promotores del estado unitario tienen por objeto establecer el sistema del partido único, el reciente desarrollo del pensamiento "consocional" ha promovido gran inquietud en las filas marxistas, ya que perciben que, con la manipulación de las diferencias, se pretende desbaratar la lucha de clases. Se duda y tal vez con fundamento el "consocionalismo" pueda resolver el conflicto de clases en beneficios de las clases más bajas, poniendo énfasis, no en situaciones económicas, sino en aspectos de antropología cultural.

Las críticas marxistas suelen centrarse en tres aspectos:

1. Este tipo de democracia desorganiza las fuerzas que buscan el cambio social.

Cada forma de participación se enfrenta a distintas reacciones. Hay quienes creen en el sistema y quienes no. Esto crea una situación en que las fuerzas del cambio son imposibles de controlar en una dirección determinada.

2. Cualquier forma de participación limita la libertad de los que participan.

Por el solo hecho de participar (negociar) uno se está estableciendo limitaciones y otorgando concesiones. Aun cuando no se crea en el sistema, el actuar dentro de él guía la propia acción de acuerdo a la lógica del sistema.

3. Cualquier forma de participación obedece a su propia lógica de lucha política, lo cual sitúa a los distintos individuos y grupos en distintas posiciones estratégicas dentro del campo de la lucha social.

El sistema acoge las demandas de parte de los ciudadanos o parte de las demandas y los ubica en diferentes posiciones en la jerarquía social teniendo esta mecánica como efecto que los prerrequisitos para la protesta colectiva sean sumamente difíciles de organizar.

Existe una cuarta crítica que ya no está orientada a la democracia consocional en sí misma sino al concepto de legitimidad.

Para quienes consideran como base de la legitimidad del ejercicio del poder tan sólo el equilibrio entre una relación de fuerzas, la estabilidad del sistema social se puede romper sólo cuando las ideologías básicas de los actores colectivos sufre transformaciones cruciales entre la relación del poder y dichos actores; es por ello 
que, a juicio de éstos, la falta de consenso de por sí no produce falta de legitimidad. Como ejemplo citan que una dictadura no cae por falta de popularidad sino por un cambio en las relaciones de las fuerzas que la sustentan.

La proposición "consocional" no requiere necesariamente un establecimiento constitucional, puede ser el resultado de una práctica política, que necesita de un constante ejercicio, madurez y convencimiento entre quienes la desarrollan. La idea fundamental es la toma de decisiones a nivel de todas las elites, amparando los derechos en los intereses propios, reemplaza el concepto de usurpación del poder por el del ejercicio compartido, con ello destruye la base de la democracia liberal que el marxismo requiere para poder operar. A su vez elimina las odiosidades del totalitarismo.

Se trata de una proposición que requiere de un mayor estudio. No es el resultado de una lucubración académica sino de la observación de la existencia de distintos elementos de "consocionalismo" en diferentes sociedades frente a problemas distintos pero similares.

Lijphart ha reunido estas observaciones en un planteamiento teórico único, pero no indica que sea necesaria la concurrencia de todos sus elementos para su vigencia plena.

El tema de la participación plural en el ejercicio del poder político, como modelo opuesto al del dominio de las mayorías con exclusión de las minorías, da lugar a una multiplicidad de debates que van más allá del punto central planteado por Lijphart que dice relación con un equilibrio y una participación más democrática del sistema político, orientada a otorgar una base de mayor legitimidad al poder político del Estado.

En efecto, si analizamos la situación en mayor detalle, veremos que hay una revisión de una serie de conceptos clásicos emanados del hecho que, en la democracia "consocional", la negociación política adquiere una importancia clave para lograr el consenso que se requiere a fin de producir la dinámica del modelo.

El concepto de negocio político, como acuerdo de voluntades destinado a crear, modificar o extinguir efectos políticos adquiere una trascendencia mayor que en ningún otro sistema, pues origina resultados en todas las esferas de la vida en sociedad.

La doctrina clásica considera que los actos autoritativos del Estado se materializan en las leyes, considerando a ésta como la principal forma de normatividad de la vida en sociedad. Pero el ejercicio de prácticas "consocionales" ha dado origen a categorías tales como "mercado político", "intercambio político", y "voto de intercambio" (renuncia al uso del Veto a condición de que la otra parte no haga uso de 
él) que alteran el concepto clásico del poder político, sustentándose éste más en el acuerdo de voluntades o consenso que en el acto impositivo emanado de la ley.

La esfera del ejercicio del poder del gobierno no está en la sola autoridad de la ley sino en la obediencia de la norma aceptada por consenso. En este panorama la ley (cualquiera sea su forma) será efectiva y no sólo un acto formal, en la medida en que ella haya sido negociada por los grupos interesados y afectados. En el proceso de negociación del acto político se produce un intercambio de recursos entre los grupos que serán afectados por la medida. En este proceso las partes pueden poner a disposición del Estado algunos recursos o renunciar al uso de otros. Este acuerdo entre las partes es de vital importancia, pues desde allí se genera el poder político del gobernante; ya no se trata de un acto impositivo de éste basado en una ley generada en la imposición de la mayoría que, por una ficción legal, ha de ser considerada la expresión de la voluntad soberana. En el proceso del llamado "intercambio político" los actores se reúnen con el gobernante a negociar los alcances de la medida que se desea adoptar. En el consenso se determinan los ámbitos del acto político que el gobierno a través de los recursos del Estado pondrá en ejecución.

En este modelo, contrario a lo que opinan algunos autores, estamos en presencia de un verdadero contrato social, específico y determinado. Este acto político emanado del consenso contará, en su naturaleza, con absoluta y real legitimidad; la desobediencia civil y la necesidad de coerción para el cumplimiento de la norma se reducen al mínimo. Otra característica que surge del negocio político consensual es que el acto público se asemeja cada vez más a un acto de derecho privado ya que éste es el resultado del trato entre las partes, situación completamente distinta al tradicional concepto de una relación vertical de gobernante a gobernado.

En un sistema o práctica de este tipo, la política se socializa y las esferas sociales y económicas cada vez se politizan más, especialmente en materias que se refieren a la conducción de la "polis".

Enfocado el fenómeno bajo otro punto de vista presenciamos la interpenetración de las esferas públicas y privadas en materias decisorias de gobierno. Por una parte el "sector privado" en el proceso de negociación entrega facultades al "sector público" en materias de su dominio y, en compensación, el "sector público" entrega al privado facultades de su área, ya sea por actuación o renuncia en el actuar. Esta situación, que algunos autores italianos (Bobbio entre otros) llaman privatización de la ley, produciría una mayor debilidad de la autoridad del Estado ayudando a la descomposición del mismo.

Luego, con esta práctica "consocional", en algunos casos neocorporativa, no se solucionaría el problema de la crisis del Estado causada por deterioro de la legitimidad. Nos encontrariamos frente a la paradoja de que por un exceso de legitimidad se haría innecesaria la existencia de la autoridad soberana del Estado. 
No habría un poder político permanente y general del Estado sino por y para cada negocio en particular.

Una atomización del poder político, según los críticos, más la autonomía de los segmentos de la sociedad plural, puede disminuir de tal manera la función unitaria del Estado que la sociedad política podría caer en un separatismo que la haría desaparecer como un solo ente.

Este discurso nos lleva a considerar el origen de toda la proposición. Sin considerar al caso de la violación individual de la norma, la decisión aprobada por la mayoría (como en el sistema "Westminsteriano") exige la existencia de una autoridad coercitiva que imponga esta voluntad incluso a las minorias. El poder del Estado se aplica especialmente a la minoría que no ha participado en el acuerdo de la norma; pero si nos encontramos ante una norma, resultado del consenso, el Estado no tendría necesidad de coaccionar para lograr su aprobación y cumplimiento general.

El desarrollo de estos conceptos nos lleva a una distinta apreciación de la naturaleza del poder. El poder ya no es una facultad que se posee y que se ejerce en contra de otros, sino el resultado de una relación entre los actores del negocio politico.

El consenso político produce el traslado del poder político de manos de un árbitro (el gobernante) a manos de una elite del grupo o segmento. Es un fenómeno de recuperación del poder que hace posible el intercambio en la negociación. EI segmento o grupo al recuperar poder está en condiciones de volver a entregar parte de él en cada negociación específica.

En consecuencia tenemos intercambio político en la negociación cuando el Estado permite a las organizaciones, grupos o segmentos influir en el proceso de toma de decisiones y su implementación y ejecución de tal manera que pueden beneficiarse de sus recursos materiales, coercitivos y simbólicos a cambio de lo cual las organizaciones de intereses otorgan su consenso al Estado facilitando sus recursos económicos, organizacional e ideología.

En la negociación de intercambio político el Estado negocia poder político por poder social y económico, podemos concluir que el poder de negociación de las partes va a emanar del margen de libertad con que cuentan para rechazar las proposiciones de la o las partes. Este margen de libertad estaría basado a su vez en el grado de autonomía de los segmentos.

\section{VI}

De lo anteriormente expuesto podemos sacar diversas conclusiones. En las democracias liberales la dinámica política es el resultado de una dialéctica entre oposición y gobierno, entre mayorías y minorías excluidas de toda participación. El acto 
político de gobierno está supeditado, más que al interés nacional, a la mantención de una situación de apoyo mayoritario que le permita la perpetuación del poder.

En la proposición "consocional", por la naturaleza de la participación que origina un negocio político cuyos resultados afectarán a todas las partes comprometidas, la dinámica política es originada por una voluntad común orientada a intereses comunes. La lucha por el poder político decrece, pues todos los afectados por su ejercicio participan en él. Si el negocio político según algunos críticos, privatiza el Estado ello tiene por último la ventaja que, en los mismos términos del derecho privado, ante los actos políticos resultantes del negocio político la inoponibilidad es inexistente.

Otro aspecto que estimamos interesante destacar son las condiciones en que surge la subsidiaridad. Para lograr decisiones favorables a sus intereses en el proceso de negociación los grupos tienden a obtener una mayor autonomía y autosuficiencia, toda vez que la capacidad de negociación de las partes está definida por el grado de libertad para negarse a la voluntad adversa. Esta situación se traduce en que el reclamo que el grupo plantea en la mesa de negociación sea netamente subsidiario, es decir, tiene lugar cuando no puede satisfacer sus requerimientos por sí mismo teniendo que recurrir a la acción y cooperación del Estado y los otros grupos.

Como hemos manifestado al comienzo de este artículo, a partir de las observaciones de diversas prácticas políticas en determinadas sociedades se han seleccionado diversas características con las cuales se ha estructurado un modelo teórico. No se conoce hasta el momento una sociedad organizada políticamente de acuerdo a la totalidad de este modelo. En todas y cada una de las sociedades analizadas surgen uno u otro elemento "consocional" ya sea que estén consagrados en la ley, la Constitución o en la mera práctica o costumbre.

Este aspecto de la proposición "consocional" la hace interesante, ya que cualquiera de sus elementos puede practicarse en cualquier sociedad política según las circunstancias lo requieran. 